\title{
Functional Anatomy of the Female Pelvic Floor
}

\author{
JAMES A. ASHTON-MILLER ${ }^{a}$ AND JOHN O. L. DELANCEY ${ }^{b}$ \\ ${ }^{a}$ Department of Mechanical Engineering, Biomedical Engineering, and Institute \\ of Gerontology, University of Michigan, Ann Arbor, Michigan, USA \\ ${ }^{b}$ Department of Obstetrics and Gynecology, University of Michigan, Ann Arbor, \\ Michigan, USA
}

\begin{abstract}
The anatomic structures in the female that prevent incontinence and genital organ prolapse on increases in abdominal pressure during daily activities include sphincteric and supportive systems. In the urethra, the action of the vesical neck and urethral sphincteric mechanisms maintains urethral closure pressure above bladder pressure. Decreases in the number of striated muscle fibers of the sphincter occur with age and parity. A supportive hammock under the urethra and vesical neck provides a firm backstop against which the urethra is compressed during increases in abdominal pressure to maintain urethral closure pressures above the rapidly increasing bladder pressure. This supporting layer consists of the anterior vaginal wall and the connective tissue that attaches it to the pelvic bones through the pubovaginal portion of the levator ani muscle, and the uterosacral and cardinal ligaments comprising the tendinous arch of the pelvic fascia. At rest the levator ani maintains closure of the urogenital hiatus. They are additionally recruited to maintain hiatal closure in the face of inertial loads related to visceral accelerations as well as abdominal pressurization in daily activities involving recruitment of the abdominal wall musculature and diaphragm. Vaginal birth is associated with an increased risk of levator ani defects, as well as genital organ prolapse and urinary incontinence. Computer models indicate that vaginal birth places the levator ani under tissue stretch ratios of up to 3.3 and the pudendal nerve under strains of up to $33 \%$, respectively. Research is needed to better identify the pathomechanics of these conditions.
\end{abstract}

KEYWORDS: functional anatomy; female pelvic floor; levator ani muscles; urethra; prolapse; incontinence; vaginal birth

\section{INTRODUCTION}

The female pelvic floor is an understudied region of the body from a biomechanical perspective. On a daily basis, its anatomic structures must prevent

Address for correspondence: James A. Ashton-Miller, Biomechanics Research Laboratory, Department of Mechanical Engineering, G.G. Brown 3208, University of Michigan, Ann Arbor, MI 481092125. Voice: +734-763-2320; fax: +734-763-9332.

jaam@umich.edu

Ann. N.Y. Acad. Sci. 1101: 266-296 (2007). (C) 2007 New York Academy of Sciences. doi: 10.1196/annals.1389.034 
incontinence and pelvic organ prolapse during the elevations in abdominal pressure and motions associated with daily physical activities. Yet they must also permit waste to be eliminated through urination, and defecation. But unlike the male, they must also allow childbirth. Pregnancy and birth are remarkable times in a woman's life in many positive ways. Unfortunately, as we will see later in this article, for certain women changes that occur as a result of vaginal delivery during the reproductive years can lead to increased problems later in their life span that result in prolapse of the pelvic organs and urinary incontinence; problems referred to as pelvic floor dysfunction. These problems significantly affect women's quality of life and often result in the need for complex surgery that has an unfortunately high reoperation rate of approximately $30 \% .{ }^{1}$ If we are to develop better preventative strategies that spare at-risk women, but also guide us to avoid intervention in women not at risk for pelvic floor dysfunction, we must know what injuries occur in the pelvic floor that increase women's chance of developing pelvic floor dysfunction and what obstetrical factors are associated with the occurrence of these injuries. The mysterious pelvic floor changes that allow a 7.5-pound infant to pass out of the body are only now, with the help of advanced technology, being discovered.

One common type of female pelvic floor dysfunction, urinary incontinence, is a common condition, with prevalence ranging from $8.5 \%$ to $38 \%$ depending on age, parity, and definition. ${ }^{2,3}$ Most women with incontinence have stress incontinence, ${ }^{4}$ which is treated using conservative therapy or surgery. Despite the common occurrence of this problem, there have been few advances in our understanding of its cause in the past 40 years. Most of the many surgical procedures for alleviating stress incontinence involve the principle of improving bladder neck support. ${ }^{5,6}$ These treatments are empirical and the goal of selecting treatment based on specific anatomic abnormalities has awaited identification, in each case, of the muscular, neural, and/or connective tissues that have developed impairments.

A better understanding of structure-function relationships concerning how pelvic floor structures provide bladder neck support would help guide treatment selection and effect. For example, if, while giving vaginal birth, a woman sustains a partial tear of a portion of her pelvic muscles that influence her continence, then pelvic muscle exercises may be effective. On the other hand, if portions of those muscles are irretrievably lost, for example, due to complete and permanent denervation, then no amount of exercising will restore them; pelvic muscle exercises may well lead to agonist muscle hypertrophy, but whether or not this will restore continence will depend upon whether the agonist muscles can compensate for the lost muscle function. This article therefore reviews the functional anatomy of the pelvic floor structures, the effects of age on urethral support and the urethral sphincter, and attempts to clarify what is known about the different structures that influence stress continence. This mechanistic approach should help guide research into pathophysiology, treatment selection, and prevention of stress incontinence. In addition, we 
also review the structures that resist genital prolapse because vaginal delivery confers a 4 - to 11 -fold increase in risk of developing pelvic organ prolapse. ${ }^{7}$

\section{HOW IS URINARY CONTINENCE MAINTAINED?}

Urethral closure pressure must be greater than bladder pressure, both at rest and during increases in abdominal pressure to retain urine in the bladder. The resting tone of the urethral muscles maintains a favorable pressure relative to the bladder when urethral pressure exceeds bladder pressure. During activities, such as coughing, when bladder pressure increases several times higher than urethral pressure, a dynamic process increases urethral closure pressure to enhance urethral closure and maintain continence that is referred to as "pressure transmission." 8 Both the magnitude of the resting pressure in the urethra and the increase in pressure generated during a cough determine the pressure at which leakage of urine occurs. ${ }^{9}$

Although analyzing the degree of resting closure pressure and pressure transmission provides useful theoretical insights, it does not show how specific injuries to individual component structures affect the passive or active aspects of urethral closure. A detailed examination of the sphincteric closure and the urethral support subsystems ${ }^{10}$ (FIG. 1) is required to understand these relationships.

The dominant element in the urethral sphincter is the striated urogenital sphincter muscle, which contains a striated muscle in a circular configuration in the mid portion of the urethra and strap-like muscles distally. In its sphincteric portion, the urogenital sphincter muscle is intermixed with a few circular smooth muscle cells and surrounds a well-developed layer of longitudinal smooth muscle and the mucosal vascular core.

\section{The Urinary Sphincteric Closure System}

Sphincteric closure of the urethra is normally provided by these urethral striated muscles, the urethral smooth muscle, and the vascular elements within the submucosa ${ }^{11,12}$ (FIGS. 2 AND 3). Each is believed to contribute equally to resting urethral closure pressure. ${ }^{13}$

Anatomically, the urethra can be divided longitudinally into percentiles, with the internal urethral meatus representing point 0 and the external meatus representing the 100th percentile (TABLE 1). The urethra passes through the wall of the bladder at the level of the vesical neck where the detrusor muscle fibers extend below the internal urethral meatus to as far as the 15th percentile. The striated urogenital sphincter muscle (FIG. 2) begins at the termination of the detrusor fibers and extends to the 64th percentile. Its fibers are arranged tangentially in a circular configuration, surrounding the smooth muscle of 


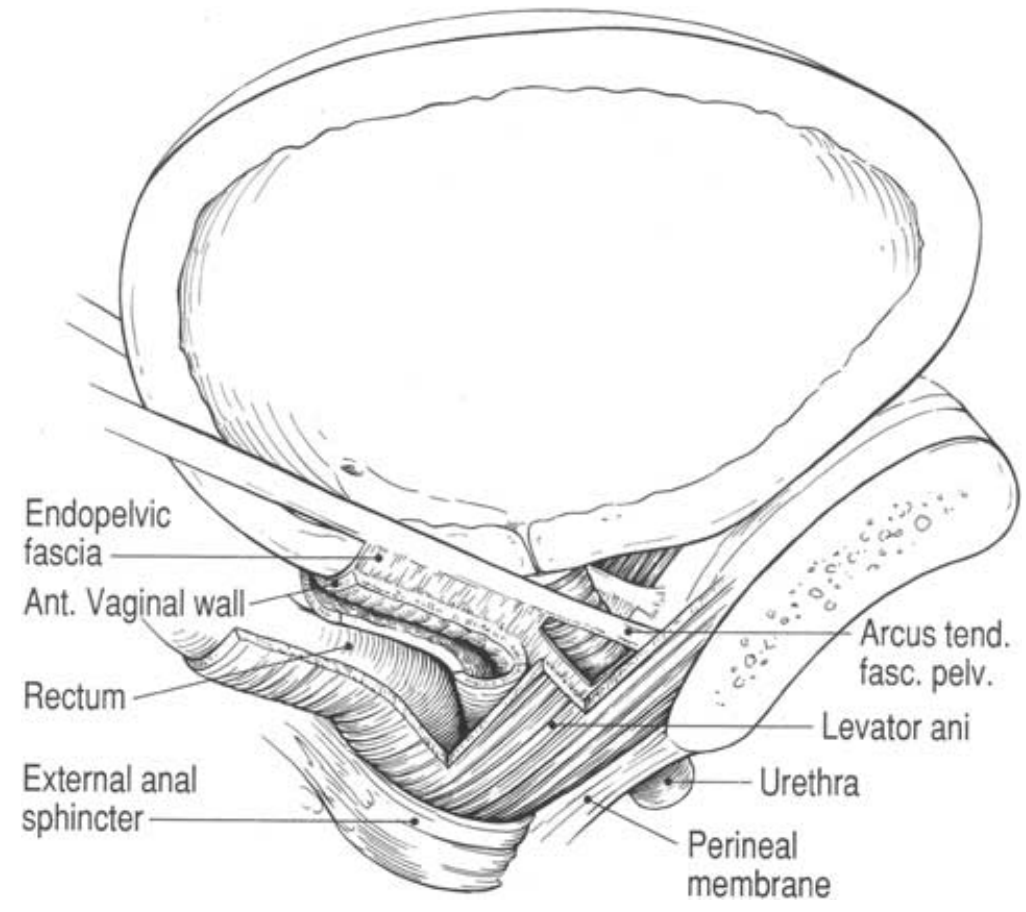

FIGURE 1. Lateral view of the components of the urethral support system. Note how the levator ani muscles support the rectum, vagina, and urethrovesical neck. Also note how the endopelvic fascia beside the urethra attaches to the levator ani muscle; contraction of the levator muscle leads to elevation of the urethrovesical neck. Puborectalis muscle is removed for clarity. (From (c) DeLancey 2005, redrawn from DeLancey 1994, ${ }^{10}$ with permission of C.V. Mosby Company, St. Louis)

the urethral wall. In the next section, we will see that there is loss of striated urogenital sphincter muscle in the posterior aspect of the urethra with age. Hence the older female urethra depicted in Figure 2 does not show striated muscle in that region. Starting at the 54th percentile, the striated muscles of the urogenital diaphragm, the compressor urethrae, and the urethrovaginal sphincter can be seen. They are continuous with the striated urethral sphincter and extend to the 76th percentile. Their fiber direction is no longer circular. The fibers of the compressor urethrae pass over the urethra to insert into the connective tissues adjacent to the perineal membrane near the pubic ramus. The urethrovaginal sphincter surrounds both the urethra and the vagina (FIG. 4). The distal terminus of the urethra runs adjacent to, but does not connect with, the bulbocavernosus muscles. ${ }^{14}$

Functionally, the urethral muscles maintain continence in various ways. At the level of the vesical neck, just above the striated urogenital sphincter, the U-shaped loop of the detrusor smooth muscle surrounds the proximal urethra, 


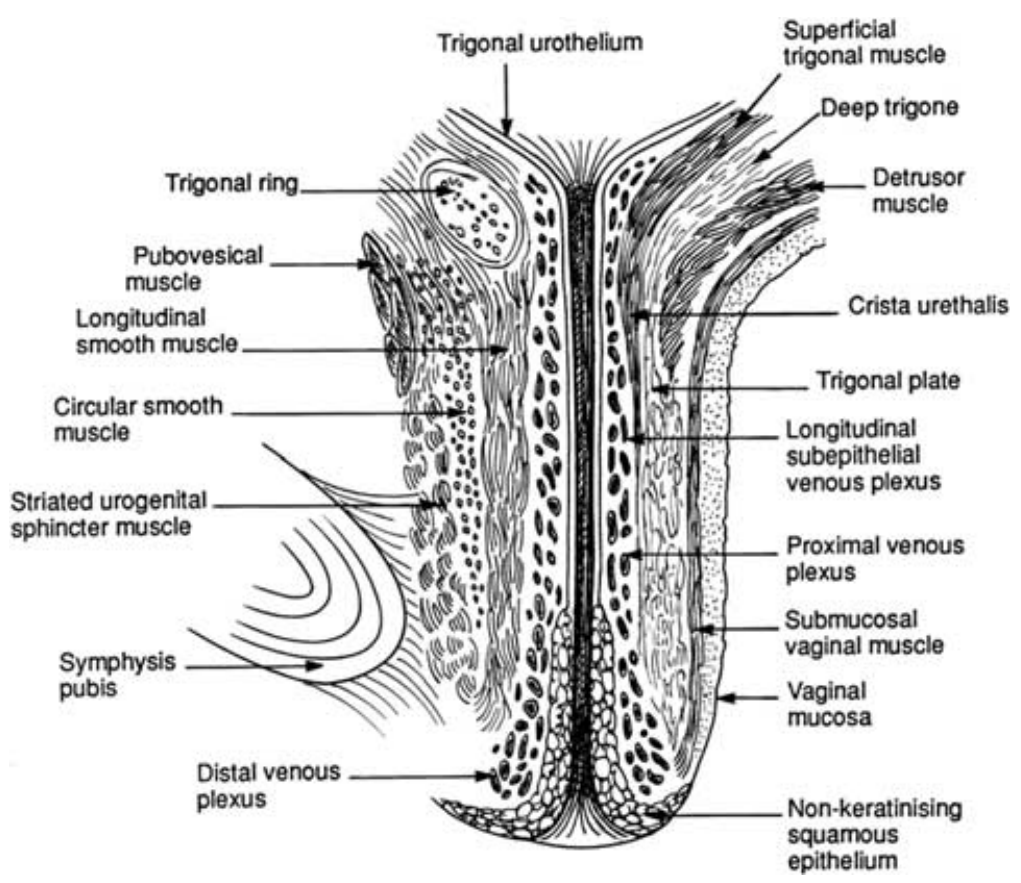

FIGURE 2. Midsagittal section showing the anatomy of the older female urethra. (c) DeLancey 1997)

favoring its closure by constricting the lumen (Fig. 4). The subjacent striated urogenital sphincter is composed mainly of type 1 (slow twitch) fibers, which are well suited to maintaining constant tone as well as allowing voluntary increases in tone to provide additional continence protection. ${ }^{15}$ Distally, the recruitment of the striated muscle of the urethrovaginal sphincter and the compressor urethrae compresses the lumen.

The urethral smooth muscle may also play a role in determining stress continence. The lumen is surrounded by a prominent vascular plexus that is believed to contribute to continence by forming a watertight seal via coaptation of the mucosal surfaces. Surrounding this plexus is the inner longitudinal smooth muscle layer, which in turn is surrounded by a circular layer that itself lies inside the outer layer of striated muscle. The smooth muscle layers are present throughout the upper four-fifths of the urethra. The circular configuration of the smooth muscle and outer striated muscle layers suggests that the contraction of these layers has a role in constricting the lumen. The mechanical role of the inner longitudinal smooth muscle layer is presently unresolved. Contraction of this longitudinal layer may help to open the lumen to initiate micturition rather than to constrict the lumen. 


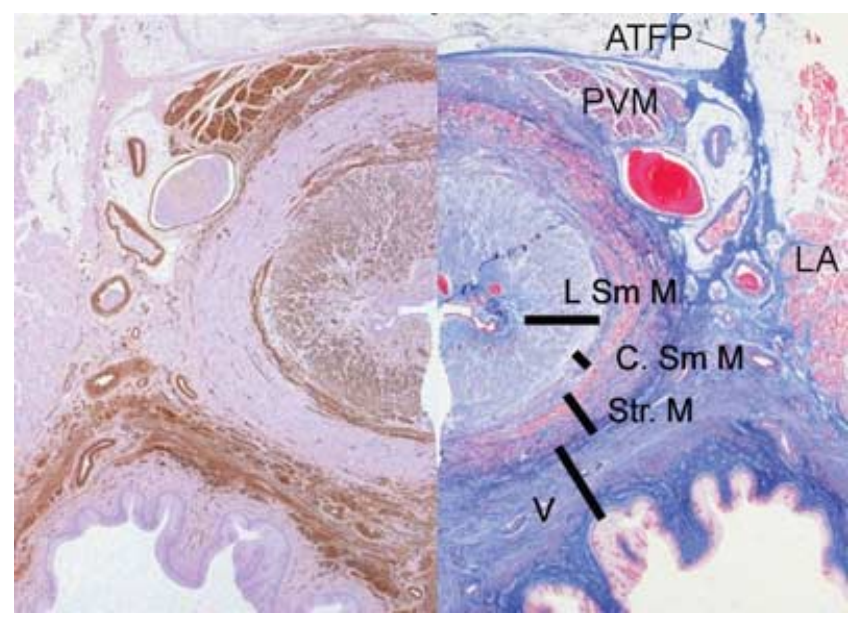

FIGURE 3. Transverse histologic section of the midurethra from a 21 -year-old woman. At left, structures are visualized using a sigma-actin smooth muscle stain. At right, the contralateral side is stained with Masson's trichrome. Shown are the pubovesical muscle (PVM), the circumferential smooth muscle (C. Sm M) surrounding the submucosa of the urethral lumen, and the longitudinal smooth muscle (L. Sm M) layer. At right, the contralateral side is stained with Masson's trichrome to show the arcus tendineus facia pelvis (ATFP), the striated urogenital sphincter muscle (Str. M), the levator ani (LA), and the anterior vaginal wall (V). (From Strohbehn, ${ }^{11}$ with permission from Lippincott Williams Wilkins, Baltimore, MD)

\section{Clinical Correlates of Urethral Anatomy and Effects of Aging}

There are several important clinical correlates of urethral muscular anatomy. Perhaps the most important is that stress incontinence is caused by problems with the urethral sphincter mechanism as well as with urethral support. Although this is a relatively new concept, the supporting scientific evidence is strong. ${ }^{16}$ The usual argument for urethral support playing an important role in

TABLE 1. Urethral topography and urethral and paraurethral structures

\begin{tabular}{|c|c|c|}
\hline \multirow[b]{2}{*}{$\begin{array}{l}\text { Percentile of } \\
\text { urethral length }\end{array}$} & \multicolumn{2}{|r|}{ Location } \\
\hline & $\begin{array}{l}\text { Region of } \\
\text { the urethra }\end{array}$ & Structures \\
\hline $0-20$ & Intramural & Internal urethral meatus detrusor loop \\
\hline $20-60$ & Mid urethra & Striated urogenital sphincter muscle smooth muscle \\
\hline $60-80$ & $\begin{array}{l}\text { Urogenital } \\
\text { diaphragm }\end{array}$ & $\begin{array}{l}\text { Compressor urethrae muscle urethrovaginal } \\
\text { sphincter smooth muscle }\end{array}$ \\
\hline $80-100$ & Distal urethra & Bulbo cavernosus muscle \\
\hline
\end{tabular}

Based on unpublished historical data. 


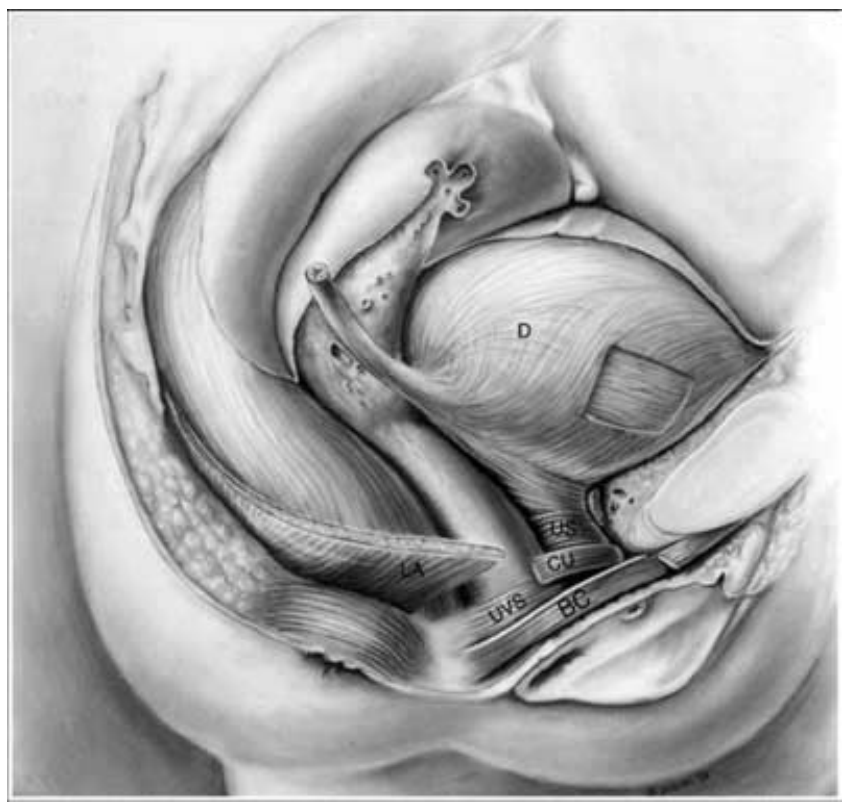

FIGURE 4. Lateral view of urethral and pelvic floor muscular anatomy. BC denotes bulbocavernosus; CU, compressor urethrae; D, detrusor; LA, levator ani; US, urethral sphincter; UVS, urethrovaginal sphincter. Puborectalis muscle is removed for clarity. (C) DeLancey 2004).

stress incontinence is that urethral support operations cure stress incontinence without changing urethral function. Unfortunately, this logic is just as flawed as suggesting that obesity is caused by an enlarged stomach because gastric stapling surgery, which makes the stomach smaller, is effective in alleviating obesity. The fact that urethral support operations cure stress incontinence does not necessarily identify urethral hypermobility as the cause of stress incontinence.

Most studies have shown not only that resting urethral closure pressures are higher in normal women compared to those with stress incontinence, but also that the severity of stress incontinence correlates quite well with resting urethral closure pressure. Loss of urethral closure pressure probably results from age-related deterioration of the urethral musculature as well as from neurologic injury. ${ }^{17-20}$ For example, the total number of striated muscle fibers within the ventral wall of the urethra has been found to decrease sevenfold as women progress from 15 to 80 years of age, with an average loss of $2 \%$ per year ${ }^{21}$ (FIG. 5). Because the mean fiber diameter does not change significantly with age, the cross-sectional area of striated muscle in the ventral wall decreases significantly with age; however, nulliparous women seemed relatively protected. $^{22}$ This $65 \%$ age-related loss in the number of striated muscle fibers 


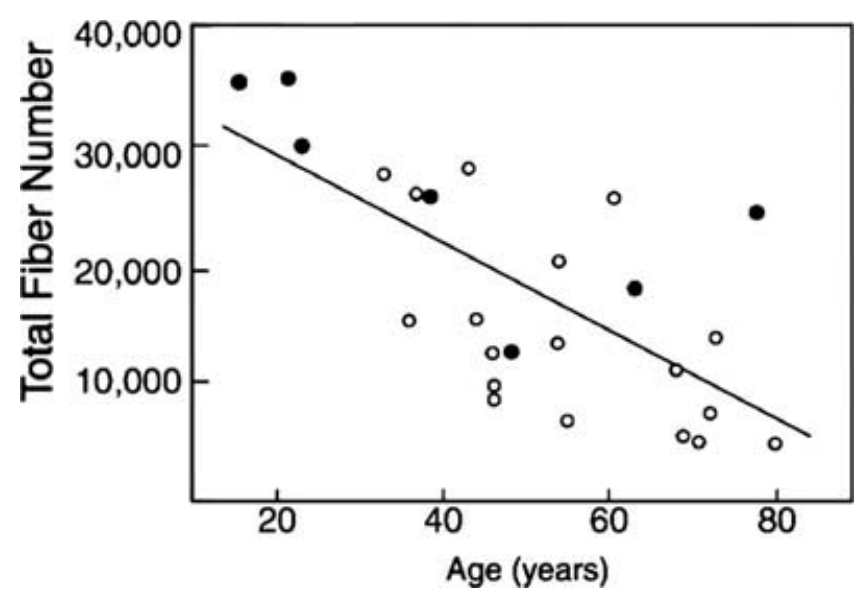

FIGURE 5. Decrease in total number of striated muscle fibers found in the ventral wall with age. The closed circles denote data from nulliparous women, and the open circles denote data from parous women. (From Perruchini et al 2002a, ${ }^{21}$ with permission of C.V. Mosby Company, St. Louis)

found in post mortem specimens is consistent with the 54\% age-related loss in closure pressure found in vivo by Rud, ${ }^{13}$ suggesting that it may be a contributing factor. However, prospective studies are needed to directly correlate the loss in the number of striated muscle fibers with a loss in closure pressure in vivo.

It is noteworthy that in our post mortem study, thinning of the striated muscle layers was particularly evident in the proximal vesical neck and along the dorsal wall of the urethra in older women. ${ }^{22}$ The concomitant sevenfold age-related loss of nerve fibers in these same striated urogenital sphincters (FIG. 6) directly correlated with the loss in striated muscle fibers (FIG. 7) in the same tissues, ${ }^{23}$ and the correlation supports the hypothesis of a neurogenic source for stress urinary incontinence and helps to explain why faulty innervation could affect continence.

We believe that the ability of pelvic floor exercise to compensate for this age-related loss in sphincter striated muscle may be limited under certain situations. Healthy striated muscle can increase its strength by about $30 \%$ after an intensive 8-12 week progressive resistance training intervention. ${ }^{24}$ Imagine an older woman whose maximum resting urethral closure pressure was $100 \mathrm{~cm}$ $\mathrm{H}_{2} \mathrm{O}$ when she was young but is now $30 \mathrm{~cm} \mathrm{H}_{2} \mathrm{O}$ due to loss of striated sphincter muscle fibers. Assume that she successfully increases her striated urogenital sphincter muscle strength by $30 \%$ through an exercise intervention. If there is a one-to-one correspondence between striated urogenital sphincter muscle strength and resting closure pressure, she will only be able to increase her resting closure pressure by $30 \%$, from $30 \mathrm{~cm} \mathrm{H}_{2} \mathrm{O}$ to $39 \mathrm{~cm} \mathrm{H}_{2} \mathrm{O}$, an increment 


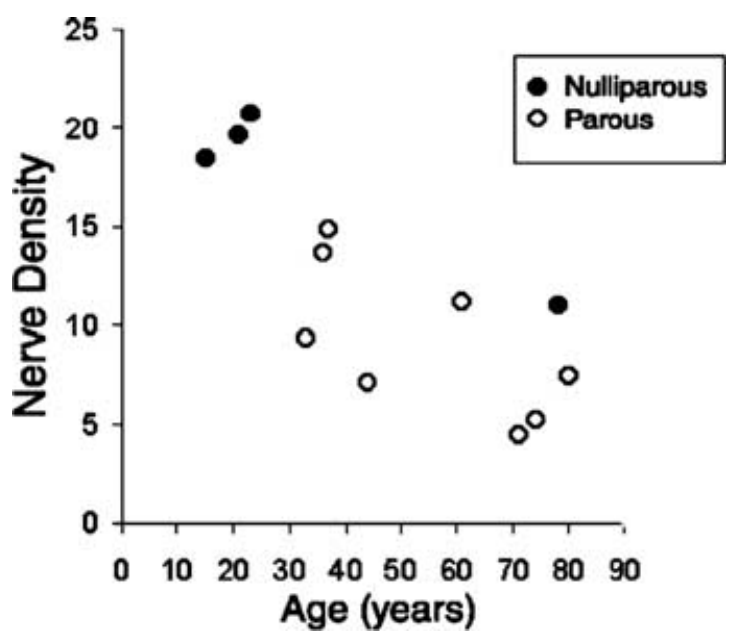

FIGURE 6. Decreasing nerve density (number per square millimeter) in the ventral wall of the urethra with age. This is a subgroup of the data in FIGURE 5 (Perucchini et al. $\left.2002 \mathrm{a}^{21}\right)$. The closed circles denote data from nulliparous women, and the open circles denote data from parous women. (From Pandit, M., J.O.L. DeLancey, J.A. Ashton-Miller, et al. $2000^{23}$ with permission of Lippincott Williams \& Wilkins, Baltimore, MD)

less than one-tenth of the $100 \mathrm{~cm} \mathrm{H}_{2} \mathrm{O}$ increase in intravesical pressure that occurs during a hard cough. It remains to be determined whether pelvic floor muscle exercise is as effective in alleviating stress incontinence in women

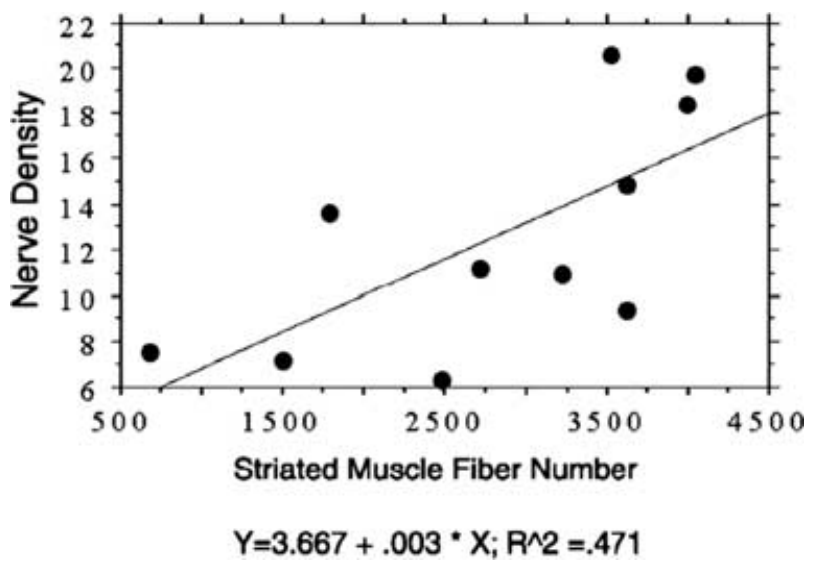

FIGURE 7. Correlation between nerve density (number per square millimeter) and total fiber number in the ventral wall of the urethra. No distinction is made between nulliparae and primiparae (Perucchini et al. 2002 $\mathrm{a}^{21}$ ). (From Pandit, M., J.O.L. DeLancey, J.A. AshtonMiller, et al. $2000,{ }^{23}$ with permission of Lippincott Williams \& Wilkins, Baltimore, MD) 
with low resting urethral pressures as it can be in women with higher resting pressures, especially for women participating in activities with large transient increases in abdominal pressure.

It is our working hypothesis that both urethral support and urethral constriction contribute to continence. Support of the urethra and vesical neck depends upon intact endopelvic fascia of the anterior vaginal wall as well as its fascial connections to the arcus tendineus fascia pelvis and to the medial portion of the levator ani muscle. The stiffness of the supportive layer under the vesical neck provides a backstop against which abdominal pressure compresses the urethra. So active constriction of the urethral sphincter maintains urine in the bladder at rest. And during increases in abdominal pressure, the vesical neck and urethra are compressed to a closed position when the raised abdominal pressure surrounding much of the urethra exceeds the fluid pressure within the urethral lumen (FIG. 1). The aspects of pelvic floor function that are relevant to stress urinary incontinence are thus urethral closure pressure at rest, the increase in urethral closure pressure caused primarily by radial compression of the urethral wall due to the increase in abdominal pressure, and secondarily by a small increase in closure pressure due to the timely recruitment of the striated sphincter muscle.

\section{URETHRAL AND VAGINAL WALL SUPPORT SYSTEM}

Support of the urethra and distal vaginal wall is inextricably linked. For much of its length, the urethra is fused with the vaginal wall, and the structures that determine urethral position and distal anterior vaginal wall position are the same. The anterior vaginal wall and urethral support system consists of all the structures extrinsic to the urethra that provide a supportive layer on which the proximal urethra and mid urethra rest. ${ }^{10}$ The major components of this supportive structure are the vaginal wall, the endopelvic fascia, the arcus tendineus fasciae pelvis, and the levator ani muscles (FIG. 1).

The endopelvic fascia is a dense, fibrous connective tissue layer that surrounds the vagina and attaches it to each arcus tendineus fascia pelvis laterally. Each arcus tendineus fascia pelvis in turn is attached to the pubic bone ventrally and to the ischial spine dorsally. The arcus tendineus fasciae pelvis is tensile structures located bilaterally on either side of the urethra and vagina. They act like the cable of a suspension bridge that is supported at each end to the pelvis and provides attachment points along its length for the supports needed to suspend the urethra on the anterior vaginal wall. Although it is well defined as a fibrous band near its origin at the pubic bone, the arcus tendineus fascia pelvis becomes a broad aponeurotic structure as it passes dorsally to insert into the ischial spine. It therefore appears as a sheet of fascia as it fuses with the endopelvic fascia, where it merges with the levator ani muscles (FIG. 1). 


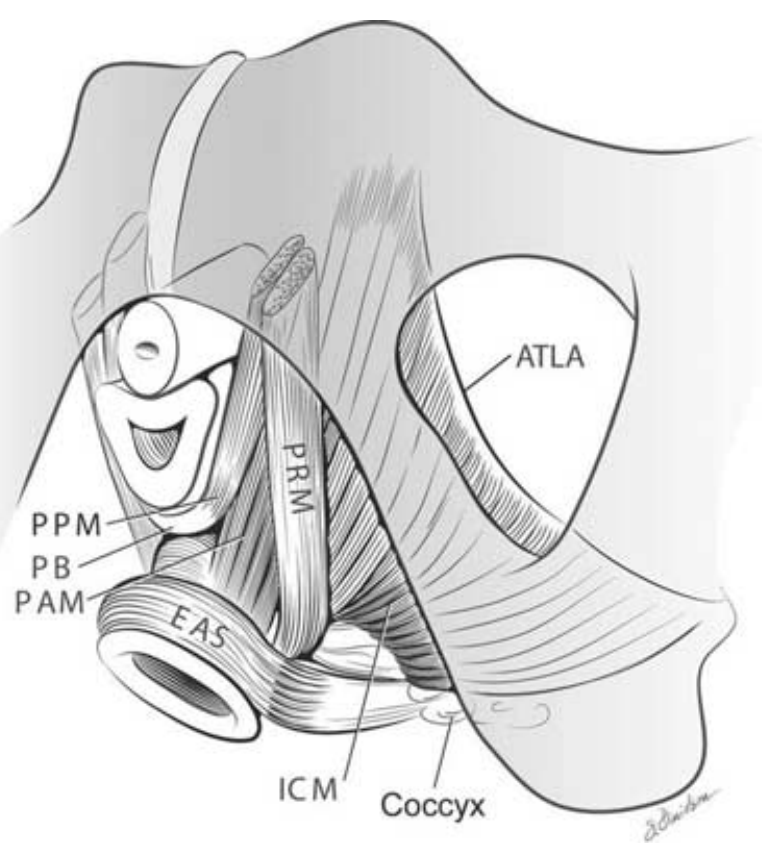

FIGURE 8. Correlation between nerve density (number per square millimeter) and total fiber number in the ventral wall of the urethra. No distinction is made between nulliparae and primiparae (Perucchini et al. 2002a ${ }^{21}$ ). (From Pandit, M., J.O.L. DeLancey, J.A. AshtonMiller, et al. $2000,{ }^{23}$ with permission of Lippincott Williams \& Wilkins, Baltimore, MD)

\section{Levator Ani Muscles}

The levator ani muscles also play a critical role in supporting the pelvic organs ${ }^{25-27}$ Not only has evidence of this been seen in magnetic resonance scans ${ }^{28,29}$ but histological evidence of muscle damage has been found ${ }^{30}$ and tied to operative failure. ${ }^{31}$ There are three basic regions of the levator ani muscle $^{31}$ (FIGS. 8 AND 9). The first region is iliococcygeal portion that forms a relatively flat, horizontal shelf, which spans the potential gap from one pelvic sidewall to the other. The second portion is the pubovisceral muscle that arises from the pubic bone on either side attaching to the walls of the pelvic organs and perineal body. The pubovisceral muscle itself consists of three subdivisions: the puboperineus (inserting into perineal body), the pubovaginalis (inserting onto the vaginal wall), and the puboanalis (inserting into the intersphincteric groove of the anal canal). The third portion of the levator muscle, the puborectal muscle, forms a sling around and behind the rectum just cephalad to the external anal sphincter. The connective tissue covering on both superior and inferior surfaces is called the superior and inferior fascia of the levator ani. When these muscles and their associated fascia are considered together, the combined structures make up the pelvic diaphragm. 


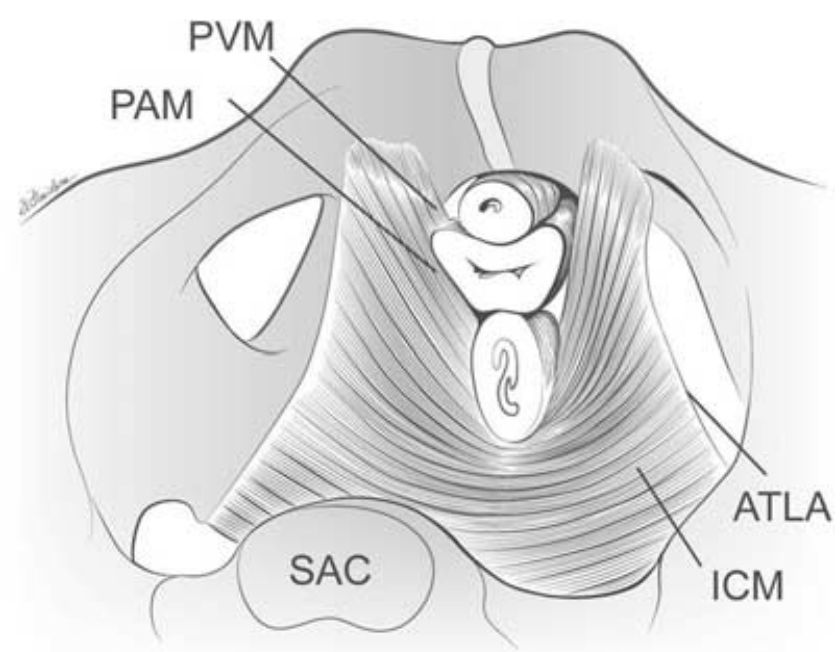

FIGURE 9. The levator ani muscle seen from above looking over the sacral promontory (SAC) showing the pubovaginal muscle (PVM). The urethra, vagina, and rectum have been transected just above the pelvic floor. PAM denotes puboanal muscle; ATLA: arcus tendineus levator ani; and ICM: iliococcygeal muscle. (The internal obturator muscles have been removed to clarify levator muscle origins.)(From Kearney et al. 2004, ${ }^{32}$ with permission of Elsevier North Holland, New York, (c) DeLancey 2003)

The opening within the levator ani muscle through which the urethra and vagina pass (and through which prolapse occurs), is called the urogenital hiatus of the levator ani. The rectum also passes through this opening, but because the levator ani muscle attaches directly to the anus it is not included in the name of the hiatus. The hiatus, therefore, is supported ventrally (anteriorly) by the pubic bones and the levator ani muscles, and dorsally (posteriorly) by the perineal body and external anal sphincter.

The normal baseline activity of the levator ani muscle keeps the urogenital hiatus closed by compressing the vagina, urethra, and rectum against the pubic bone, the pelvic floor, and organs in a cephalic direction. ${ }^{33}$ This constant activity of the levator ani muscle is analogous to that in the postural muscles of the spine. This continuous contraction is also similar to the continuous activity of the external anal sphincter muscle and closes the lumen of the vagina in a manner similar to that by which the anal sphincter closes the anus. This constant action eliminates any opening within the pelvic floor through which prolapse could occur.

A maximal voluntary levator ani muscle contraction causes the pubovisceral muscles and the puborectalis muscles to further compress the mid urethra, distal vagina, and rectum against the pubic bone distally and against abdominal hydrostatic pressure more proximally. It is this compressive force and pressure 
that one feels if one palpates a pelvic floor muscle contraction intravaginally. Contraction of the bulbocavernosus and the ventral fibers of the iliococcygeus will only marginally augment this compression force developed by the pubovisceral and puborectalis muscles. This is because the former develops little force and the latter is located too far dorsally to have much effect intravaginally. Finally, maximal contraction of the mid and dorsal ilioccyggeus muscles elevates the central region of the posterior pelvic floor, but likely contributes little to a vaginal measurement of levator strength or pressure because they do not act circumvaginally.

\section{Interactions between the Pelvic Floor Muscles and the Endopelvic Fascia}

The levator ani muscles play an important role in protecting the pelvic connective tissues from excess load. Any connective tissue within the body may be stretched by subjecting it to a tensile force. Skin expanders used in plastic surgery stretch the dense and resistant dermis to extraordinary degrees and flexibility exercises practiced by dancers and athletes lengthen fascia, aponeuroses, and ligaments. Both of these observations underscore the adaptive nature of connective tissue when subjected to repeated tension over time. If the ligaments and fasciae within the pelvis were subjected to the continuous stress imposed on the pelvic floor by the great force of abdominal pressure, they would stretch. This stretching does not occur because the constant tonic activity of the pelvic floor muscles ${ }^{34}$ closes the urogenital hiatus and carries the weight of the abdominal and pelvic organs, hereby preventing constant strain on the ligaments and fasciae within the pelvis.

The interaction between the pelvic floor muscles and the supportive ligaments is critical to pelvic organ support. As long as the levator ani muscles function to properly maintain closure of the genital hiatus, the ligaments and fascial structures supporting the pelvic organs are under minimal tension. The fasciae simply act to stabilize the organs in their position above the levator ani muscles. When the pelvic floor muscles relax or are damaged, the pelvic floor opens and the vagina lies between the zones of high abdominal pressure and low atmospheric pressure outside the body. In this situation it must be held in place by the suspensory ligaments. Although the ligaments can sustain these loads for short periods of time, if the pelvic floor muscles do not close the pelvic floor then the connective tissue will stretch and may eventually fail, resulting in pelvic organ prolapse. The support of the uterus has been likened to a ship in its berth floating on the water attached by ropes on either side to a dock. ${ }^{35}$ The ship is analogous to the uterus, the ropes to the ligaments, and the water to the supportive layer formed by the pelvic floor muscles. The ropes function to hold the ship (uterus) in the center of its berth as it rests on the water (pelvic floor muscles). If, however, the water level were to fall far enough that the ropes would be required to hold the ship without the supporting water, the ropes would all break. The analogous situation in the 
pelvic floor involves the pelvic floor muscles supporting the uterus and vagina that are stabilized in position by the ligaments and fasciae. Once the pelvic floor musculature becomes damaged and no longer holds the organs in place, the supportive connective tissue is stretched until it fails.

The attachment of the levator ani muscles into the perineal body is important and damage to this part of the levator ani muscle during delivery is one of the irreparable injuries to pelvic floor. Recent magnetic resonance imaging (MRI) has vividly depicted these defects and it has been shown that up to $20 \%$ of nulliparous women have a visible defect in the levator ani muscle on MRI. ${ }^{36}$ The exact injury mechanism still needs more research. It is likely that this muscular damage is an important factor associated with recurrence of pelvic organ prolapse after initial surgical repair. Moreover, these defects were found to occur more frequently in those individuals complaining of stress incontinence. ${ }^{36}$ An individual with muscles that do not function properly has a problem that is not surgically correctable.

\section{PELVIC FLOOR FUNCTION RELEVANT TO STRESS URINARY INCONTINENCE}

Functionally, the levator ani muscle and the endopelvic fascia interact to maintain continence and pelvic organ support. Impairments usually become evident when the system is stressed. One such stressor is a hard cough that, driven by a powerful contraction of the diaphragm and abdominal muscles, can cause a transient increase of $150 \mathrm{~cm} \mathrm{H}_{2} \mathrm{O}$, or more, in abdominal pressure. This transient pressure increase causes the proximal urethra to undergo a downward (caudodorsal) displacement of about $10 \mathrm{~mm}$ in the mid sagittal plane that can be viewed on ultrasonography. ${ }^{37}$ This displacement is evidence that the inferior abdominal contents are forced to move caudally during a cough. Because the abdominal contents are essentially incompressible, the pelvic floor and/or the abdominal wall must stretch slightly under the transient increase in abdominal hydrostatic pressure, depending on the level of neural recruitment. The ventrocaudal motion of the bladder neck that is visible on ultrasonography indicates that it and the surrounding passive tissues have acquired momentum in that direction. The pelvic floor then needs to decelerate the momentum acquired by this mass of abdominal tissue. The resulting inertial force causes a caudal-tocranial pressure gradient in the abdominal contents, with the greatest pressure arising nearest to the pelvic floor. While the downward momentum of the abdominal contents is being slowed by the resistance to the stretch of the pelvic floor, the increased pressure compresses the proximal intraabdominal portion of the urethra against the underlying supportive layer of the endopelvic fasciae, the vagina, and the levator ani muscles.

We can estimate the approximate resistance of the urethral support layer to this displacement. The ratio of the displacement of a structure in a given 
direction to a given applied pressure increase is known as the compliance of the structure. If we divide $12.5 \mathrm{~mm}$ of downward displacement of the bladder neck (measured on ultrasonography) during a cough by the transient $150 \mathrm{~cm}$ $\mathrm{H}_{2} \mathrm{O}$ increase in abdominal pressure that causes it, the resulting ratio $(12.5 \mathrm{~mm}$ divided by $150 \mathrm{~cm} \mathrm{H}_{2} \mathrm{O}$ ) yields an average compliance of $0.083 \mathrm{~mm} / \mathrm{cm} \mathrm{H}_{2} \mathrm{O}$ in healthy nullipara. ${ }^{37}$ In other words, the cough displaces the healthy intact pelvic floor $1 \mathrm{~mm}$ for every $12 \mathrm{~cm} \mathrm{H}_{2} \mathrm{O}$ increase in abdominal pressure. (Actually, the well-known hyperelastic behavior of soft tissues leads us to expect ever smaller pelvic floor displacements as the abdominal pressure increments toward its maximum value.) The increased abdominal pressure acts transversely across the urethra, altering the stresses in the walls of the urethra so that the anterior wall is deformed toward the posterior wall, and the lateral walls are deformed toward one another, thereby helping to close the urethral lumen and prevent leakage due to the concomitant increase in intravesical pressure. If pelvic floor exercises lead to pelvic floor muscle hypertrophy, then the resistance of the striated components of the urethral support layer can also be expected to increase. This is because the longitudinal stiffness and damping of an active muscle are linearly proportional to the tension developed in the muscle ${ }^{38}$ this is partly because, for the same muscle tone, the hypertrophied muscle contains more cross-bridges in the strongly bound state (across the cross-sectional area of the muscle) and these provide greater resistance to stretch of the active muscle.

If there are breaks in the continuity of the endopelvic fascia ${ }^{39}$ or if the levator ani muscle is damaged, the supportive layer under the urethra will be more compliant and will require a smaller pressure increment to displace a given distance. For example, Howard et al. ${ }^{37}$ showed that stiffness decreased by nearly $50 \%$ in healthy primipara to $0.167 \mathrm{~mm} / \mathrm{cm} \mathrm{H}_{2} \mathrm{O}$ and increased even further in stress incontinent primipara by an additional $40 \%$ to $0.263 \mathrm{~mm} / \mathrm{cm} \mathrm{H}_{2} \mathrm{O}$. Thus, the supportive layer is considerably more compliant in these incontinent patients than in healthy women; it provides reduced resistance to deformation during transient increases in abdominal pressure so that closure of the urethral lumen cannot be ensured and stress incontinence becomes possible.

An analogy that we have used previously is attempting to halt the flow of water through a garden hose by stepping on it. ${ }^{40}$ If the hose was lying on a noncompliant trampoline, stepping on it would change the stress in the wall of the hose pipe, leading to a deformation and flattening of the hose crosssectional area, closure of the lumen, and cessation of water flow, with little indentation or deflection of the trampoline. If, instead, the hose were resting on a very compliant trampoline, stepping on the hose would tend to accelerate the hose and underlying trampoline downward because the resistance to motion (or reaction force) is at first negligible, so little flattening of the hose occurs as the trampoline begins to stretch. While the hose and trampoline move downward together, water would flow unabated in the hose. As the resistance of the trampoline to downward movement increasingly decelerates the downward 
movement of the foot and hose, flow will begin to cease. Thus, an increase in compliance of the supporting tissues essentially delays the effect of abdominal pressure on the transverse closure of the urethral lumen, allowing leakage of urine during the delay.

Additionally, the constant tone maintained by the pelvic muscles relieves the tension placed on the endopelvic fascia. If the nerves to the levator ani muscle are damaged (such as during childbirth), ${ }^{41}$ the denervated muscles would undergo atrophy and leave the responsibility of pelvic organ support to the endopelvic fascia alone. Over time, these ligaments gradually stretch under the constant load and this viscoelastic behavior leads to the development of prolapse.

There are several direct clinical applications for this information. The first concerns the types of damage that can occur to the urethral support system. An example is the paravaginal defect, which causes separation in the endopelvic fascia connecting the vagina to the pelvic sidewall and thereby reduces the stiffness of the fascial layer supporting the urethra. When this occurs, increases in abdominal pressure can no longer effectively compress the urethra against the supporting endopelvic fascia to close it during increases in abdominal pressure. When present, this paravaginal defect can be repaired surgically and normal anatomy can thus be restored.

Normal urethral support system function involves levator ani muscle contraction, which supports the urethra through the endopelvic fascia. During a cough, the levator ani muscle contracts simultaneously with the diaphragm and abdominal wall muscles to build abdominal pressure. This levator ani contraction helps to tense the suburethral fascial layer, as evidenced by decreased vesical neck motion on ultrasonographic evaluation, ${ }^{42}$ thereby enhancing urethral compression. It also protects the connective tissue from undue stresses. Using an instrumented speculum, ${ }^{43}$ the strength of the levator ani muscle has recently been quantified under isometric conditions, ${ }^{44}$ and racial differences have also been found in the levator muscle contractile properties. ${ }^{45}$

Striated muscle takes 35\% longer to develop the same force in the elderly as in young adults, and its maximum force is also diminished by about $35 \% .{ }^{46}$ These changes are not due to alterations in neural recruitment patterns but rather to age-related changes in striated muscle contractility. ${ }^{47}$ Furthermore, if the striated muscle of the levator ani becomes damaged or if its innervation is impaired, the muscle contraction will take even longer to develop the same force. This decrease in levator ani strength, in turn, is associated with decreased stiffness, because striated muscle strength and stiffness are directly and linearly correlated. ${ }^{48}$ Alternatively, if the connection between the muscle and the fascia is broken, ${ }^{49}$ then the normal mechanical function of the levator ani during a cough is lost. This phenomenon has important implications for clinical management. Recent evidence from MRI scans, reviewed in a blinded manner, shows the levator ani can be damaged unilaterally or bilaterally in certain patients. $^{36}$ 
TABLE 2. Hypothetical effects of changes in cough pressure $\left(\mathrm{cm} \mathrm{H}_{2} \mathrm{O}\right)$ and pressure transmission ratio on urethral closure pressure and the potential leakage of urine

\begin{tabular}{|c|c|c|c|c|c|c|c|c|c|c|}
\hline $\begin{array}{l}\text { Example } \\
\text { condition }\end{array}$ & Pves $_{R}$ & Pura $_{R}$ & $\begin{array}{c}\mathrm{UCP}_{\mathrm{R}} \\
\text { (Pura- } \\
\mathrm{P}_{\text {ves }} \text { ) }\end{array}$ & Cough & $\begin{array}{c}\text { PTR } \\
(\%)\end{array}$ & $\Delta$ Pura $_{c}$ & Pves $_{c}$ & Pura $_{c}$ & $\mathrm{UCP}_{\mathrm{c}}$ & Status \\
\hline 1 & 10 & 60 & +50 & 200 & 100 & 200 & 210 & 260 & +50 & C \\
\hline 2 & 10 & 60 & +50 & 200 & 70 & 140 & 210 & 200 & -10 & I \\
\hline 3 & 10 & 30 & +20 & 100 & 70 & 70 & 110 & 100 & -10 & I \\
\hline 4 & 10 & 60 & +50 & 100 & 70 & 70 & 110 & 130 & +20 & $\mathrm{C}$ \\
\hline 5 & 10 & 30 & +20 & 50 & 70 & 35 & 60 & 55 & -5 & I \\
\hline
\end{tabular}

Primary variables are shown in bold from which other pressures are derived. Parameters that have been varied are italicized to show how changes in specific parameters can change continence status. Pves $_{R}=$ vesical pressure at rest; Pura $R=$ urethral pressure at rest; $\mathrm{UCP}_{\mathrm{R}}=$ urethral closure pressure at rest; $\mathrm{PTR}=$ pressure transmission ratio; delta-Pura $=$ change in urethral pressure; $\mathrm{Pves}_{\mathrm{C}}=$ bladder pressure during cough; Pura $\mathrm{C}_{\mathrm{C}}=$ urethral pressure during cough; $\mathrm{UCP}_{\mathrm{C}}=$ urethral closure pressure during cough; $\mathrm{C}=$ continent; $\mathrm{I}=$ incontinent.

\section{URETHROVESICAL PRESSURE DYNAMICS}

The anatomical separation of sphincteric elements and supportive structures is mirrored in the functional separation of urethral closure pressure and pressure transmission. The relationships between resting urethral pressure, pressure transmission, and the intravesical pressure needed to cause leakage of urine ("leak point pressure") are central to understanding urinary continence. These relationships have been described in what we have called the "pressuregram." The constrictive effect of the urethral sphincter deforms the wall of the urethra so as to maintain urethral closure pressure above bladder pressure, and this pressure differential keeps urine in the bladder at rest. For example, if bladder pressure is $10 \mathrm{~cm} \mathrm{H}_{2} \mathrm{O}$ while urethral pressure is $60 \mathrm{~cm} \mathrm{H}_{2} \mathrm{O}$, a closure pressure of $50 \mathrm{~cm} \mathrm{H}_{2} \mathrm{O}$ prevents urine from moving from the bladder through the urethra (TABLE 2, Example 1).

Bladder pressure often increases by $200 \mathrm{~cm} \mathrm{H}_{2} \mathrm{O}$ or more during a cough, and leakage of urine would occur unless urethral pressure also increases. The efficiency of this pressure transmission is expressed as a percentage. A pressure transmission of $100 \%$ means, for example, that during a $200 \mathrm{~cm} \mathrm{H}_{2} \mathrm{O}$ increase in bladder pressure (from $10 \mathrm{~cm} \mathrm{H}_{2} \mathrm{O}$ to $210 \mathrm{~cm} \mathrm{H}_{2} \mathrm{O}$ ), the urethral pressure would also increase by $200 \mathrm{~cm} \mathrm{H}_{2} \mathrm{O}$ (from 60 to $260 \mathrm{~cm} \mathrm{H}_{2} \mathrm{O}$ ) (TABLE 2, Example 1). The pressure transmission is $100 \%$ for continent women because in this situation, the pressure differential between intravesical pressure and urethral pressure remains the same $\left(50 \mathrm{~cm} \mathrm{H}_{2} \mathrm{O}\right)$ and leakage is prevented. Pressure transmission is usually less than $100 \%$ in incontinent women, for reasons that still need to be worked out in detail. Thus abdominal pressure may increase by $200 \mathrm{~cm} \mathrm{H}_{2} \mathrm{O}$ while urethral pressure may only increase by $140 \mathrm{~cm} \mathrm{H}_{2} \mathrm{O}$, for a pressure transmission of $70 \%$ (TABLE 2, Example 2). If a woman starts with a urethral pressure of $30 \mathrm{~cm} \mathrm{H}_{2} \mathrm{O}$, resting bladder pressure of $10 \mathrm{~cm} \mathrm{H}_{2} \mathrm{O}$ and her pressure transmission is $70 \%$, then with a cough pressure of $100 \mathrm{~cm} \mathrm{H}_{2} \mathrm{O}$ 
her bladder pressure would increase to $110 \mathrm{~cm} \mathrm{H}_{2} \mathrm{O}$ while urethral pressure would increase to just $100 \mathrm{~cm} \mathrm{H}_{2} \mathrm{O}$ and leakage of urine would occur because intravesical pressure is not above urethral pressure (TABLE 2, Example 3). In TABLE 2, Example 4 shows the same elements, but with a higher urethral closure pressure; and similarly Example 5 shows what happens with a weaker cough.

According to this conceptual framework, resting pressure, pressure transmission, and cough strength are the key continence variables. What factors determine these two phenomena? How are they altered to cause incontinence? Although the pressuregram concept is useful for understanding the role of resting pressure and pressure transmission, it has not been possible to reliably make these measurements dynamically because of the rapid movement of the urethra relative to the urodynamic transducer during a cough.

\section{CLINICAL IMPLICATIONS OF LEVATOR FUNCTIONAL ANATOMY}

Pelvic muscle exercise has been shown to be effective in alleviating stress incontinence in many, but not all, women. ${ }^{50}$ Having a patient cough with a full bladder and measuring the amount of urine leakage is quite simple. ${ }^{51}$ If the

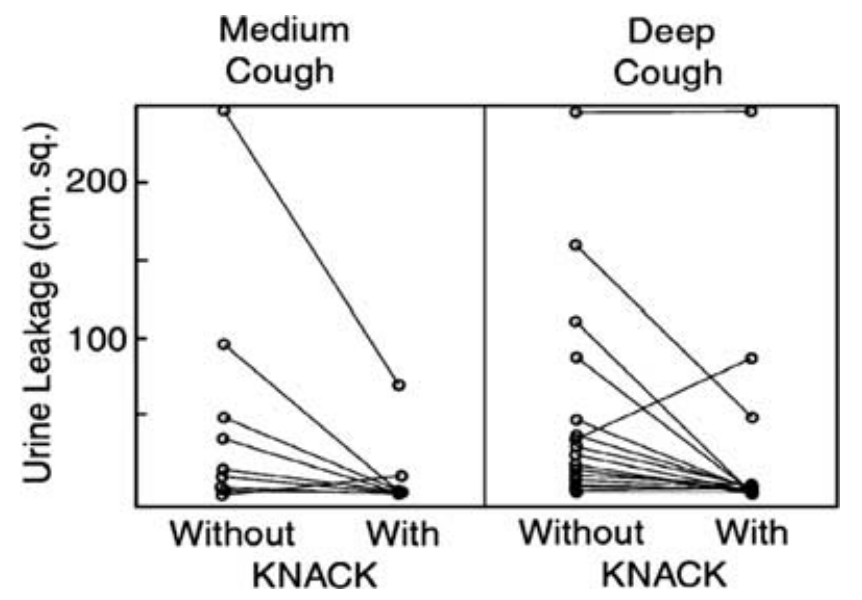

FIGURE 10. The effect of learning the 'Knack' (precontracting the pelvic muscles before a cough) on reducing the total amount of urine leaked during three separate medium intensity coughs (left panel) and during three separate deep coughs (right panel) measured one week after the women had learned the skill. Each line joins the wet area on one trifold paper towel for each of the 27 women observed coughing without the knack (denoted by 'Without Knack') with that observed on a second paper towel when the same women used the knack (denoted 'With Knack'). With regard to the units on the ordinate, a calibration test showed that every square centimeter of wetted area was caused by $0.039 \mathrm{~mL}$ urine leakage. (From Miller et al. 1998b, ${ }^{52}$ with permission of Blackwell Science, Malden, MA.) 
muscle is normally innervated and is sufficiently attached to the endopelvic fascia, and if by contracting her pelvic muscles before and during a cough a woman is able to decrease that leakage ${ }^{52}$ (FIG. 10), then simply learning when and how to use her pelvic muscles may be an effective therapy. If this is the case, then the challenge is for the woman to remember to use this skill during activities that transiently increase abdominal pressure. If the pelvic floor muscle is denervated as a result of substantial nerve injury, then it may not be possible to rehabilitate the muscle sufficiently to make pelvic muscle exercise an effective strategy. To use the remaining innervated muscle, women need to be told when to contract the muscles to prevent leakage, and they need to learn to strengthen pelvic muscles. A stronger muscle that is not activated during the time of a cough cannot prevent stress incontinence. Therefore, teaching proper timing of pelvic floor muscles would seem logical as part of a behavioral intervention involving exercise. The efficacy of this intervention is currently being tested in a number of ongoing randomized controlled trials. In addition, if the muscle is completely detached from the fascial tissues, then despite its ability to contract, the contraction may no longer be effective in elevating the urethra or maintaining its position under stress.

\section{POSTERIOR VAGINAL WALL SUPPORT AS IT APPLIES TO RECTOCELE}

The posterior vaginal wall is supported by connections between the vagina, the bony pelvis, and the levator ani muscles. ${ }^{19}$ The lower one-third of the vagina is fused with the perineal body (FIG. 11). This structure is the attachment between the perineal membranes on either side. This connection prevents downward descent of the rectum in this region. If the fibers that connect one side with the other rupture then the bowel may protrude downward resulting in a posterior vaginal wall prolapse (FIG. 12). In the mid vagina, the wall is connected to the inside of the levator ani muscles by sheets of endopelvic fascia (FIG. 13). These connections prevent the ventral movement of the vagina during increases in abdominal pressure. The medial most aspect of these paired sheets is referred to as the rectal pillars. In the upper one-third of the vagina, the vaginal wall is connected laterally and dorsally by the cardinal and vaginal portion of the uterosacral ligament. In this region there is a single attachment to the vagina, and a separate system for the anterior and posterior vaginal walls does not exist. Therefore, when abdominal pressure forces the vaginal wall downward toward the introitus, attachments between the posterior vagina and the levator muscles prevent this downward movement. The uppermost area of the posterior vagina is suspended and descent of this area is usually associated with the clinical problem of uterine and/or apical prolapse. The lateral connections of the mid vagina hold this portion of the vagina in place and prevent a mid vaginal posterior prolapse from occurring (FIG. 14). The multiple connections 

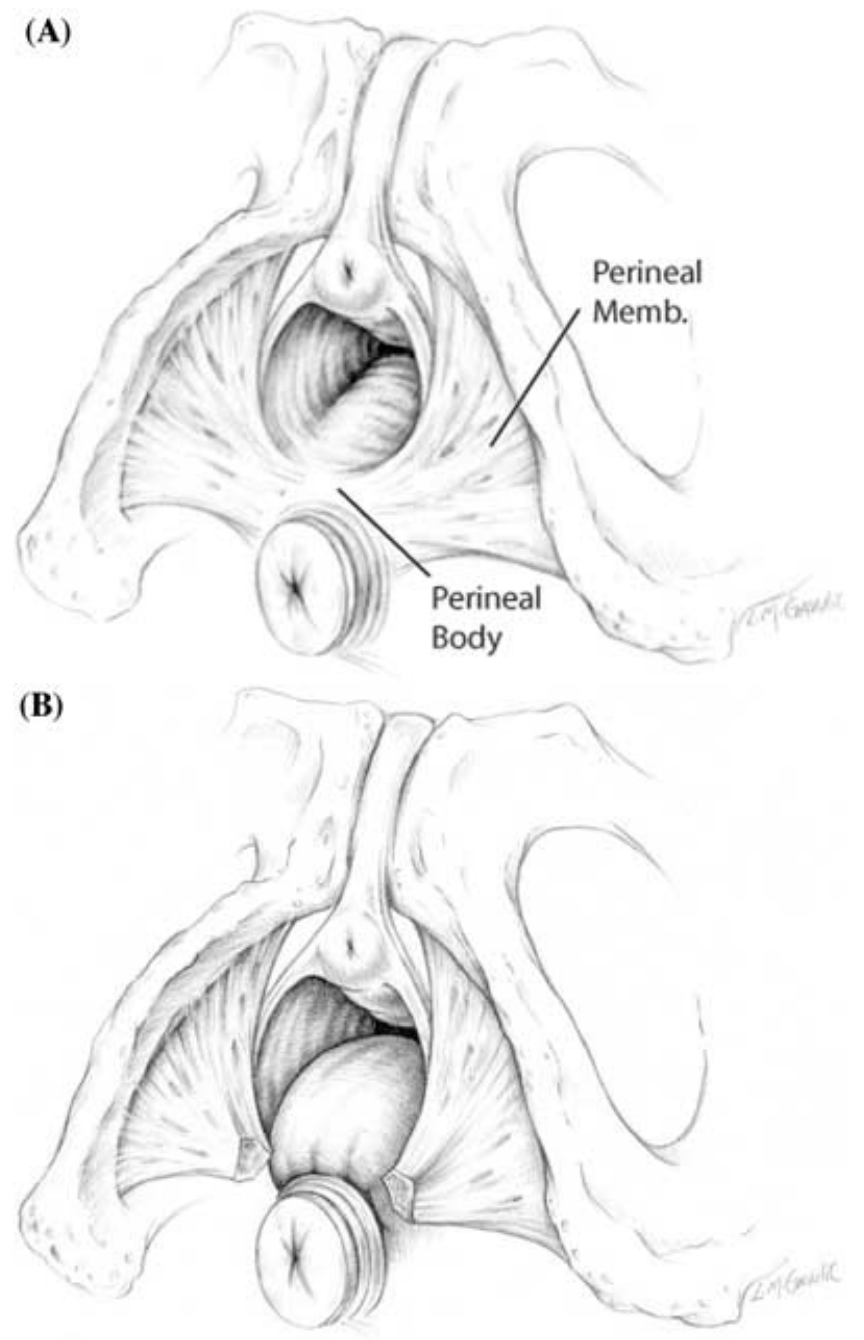

FIGURE 11. (A) The perineal membrane spans the arch between the ischiopubic rami with each side attached to the other through their connection in the perineal body. (B) Note that separation of the fibers in this area leaves the rectum unsupported and results in a low posterior prolapse. (c) DeLancey 1999)

of the perineal body to the levator muscles and the pelvic sidewall (FIGS. 15 and 16) prevent a low posterior prolapse from descending downward through the opening of the vagina (the urogenital hiatus and the levator ani muscles). Defects in the support at the level of the perineal body most frequently occur during vaginal delivery and are the most common type of posterior vaginal wall support problem. 


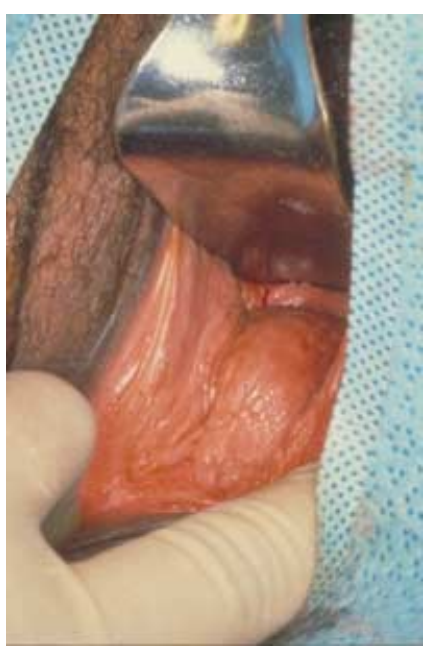

FIGURE 12. Posterior prolapse due to separation of the perineal body. Note the end of the hymenal ring that lies laterally on the side of the vagina, no longer united with its companion on the other side. (c) DeLancey 2004)

\section{SECOND STAGE OF LABOR AND VAGINAL BIRTH}

\section{Stretch of the Levator Ani}

During the second stage of labor, volitional contractions of the abdominal wall and respiratory diaphragm muscles are spontaneously timed by the mother to coincide with the peak uterine contraction to drive the fetal head through the levator hiatus. The head places the pelvic floor muscles under considerable stretch. Lien et al..$^{53}$ developed a 3D geometric model of the female pelvic floor to predict levator muscle stretch ratios during the second stage of vaginal birth. Serial magnetic resonance images from a healthy nulliparous 34-yearold woman, published anatomic data, and engineering graphics software were used to construct a geometric model of the levator ani muscles along with related passive tissues (FIG. 17). The model was used to quantify pelvic floor muscle stretch induced during the second stage of labor as a model fetal head progressively engaged and then stretched the iliococcygeus, pubococcygeus, and puborectalis muscles (FIG. 18). The results show that the pubococcygeus muscle, the shortest and most medial levator ani muscle, had the largest tissue strain with a stretch ratio ([tissue length under stretch]/[original tissue length]) of 3.26 (FIG. 19). Regions of the iliococcygeus, pubococcygeus, and puborectalis muscles reached maximal stretch ratios of 2.73, 2.50, and 2.28, respectively. Tissue stretch ratios were proportional to fetal head size: for example, increasing fetal head diameter by $9 \%$ increased medial pubococcygeus stretch by the same amount. 


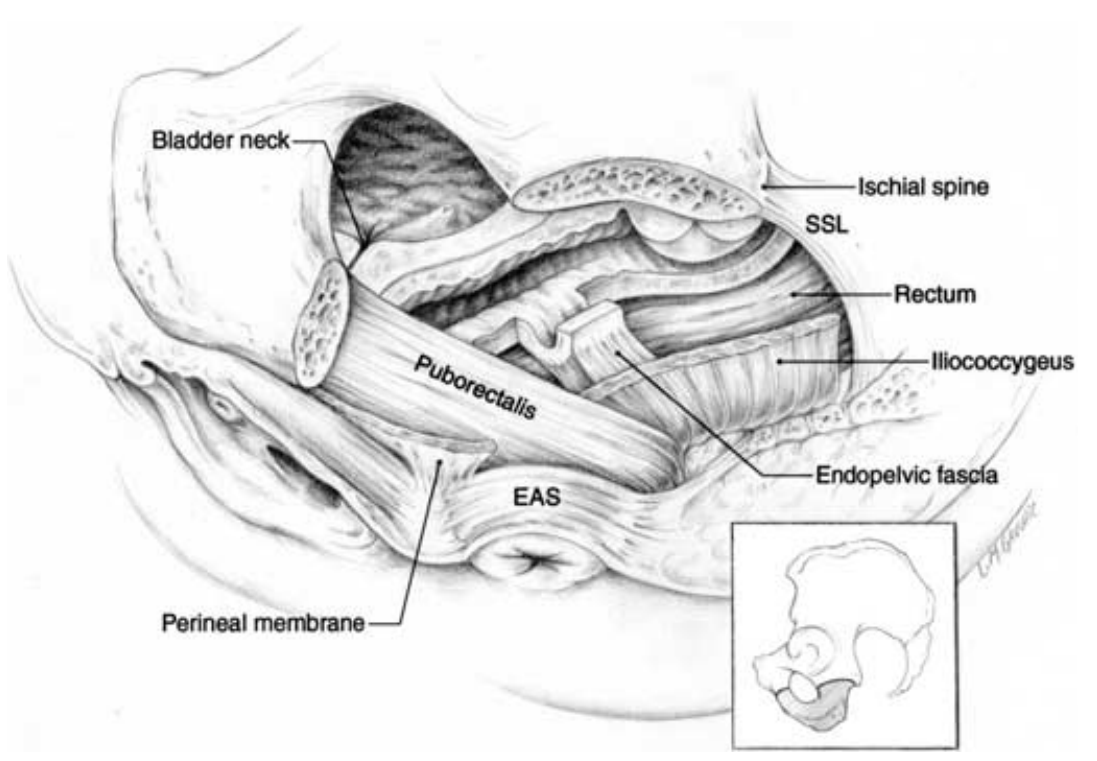

FIGURE 13. Lateral view of the pelvis showing the relationships of the puborectalis, iliococcygeus, and pelvic floor structures after removal of the ischium below the spine and sacrospinous ligament (SSL) (EAS external anal sphincter). The bladder and vagina have been cut in the midline yet the rectum left intact. Note how the endopelvic fascial 'pillars' hold the vaginal wall dorsally preventing its downward protrusion. (c) DeLancey 1999)

Among the limitations of this model were the lack of consideration of tissue stresses, the simplified fetal head geometry, and the fact that the predicted stretch ratios were average values for each muscle band. Regions of greater and lesser stretch may exist within each band, depending on local material properties. This is complicated by the muscle really being a composite structure, like the diaphragm being sandwiched between thin fascial sheets. A finite element model will give a better indication of tissue stresses and strains during birth. However, before an accurate finite element model of the pelvic floor during birth can be developed, we need to know the constitutive law and the values of ultimate tensile stress and strain of the pelvic floor muscle tissues at the time of the second stage of labor. These are completely unknown. Information will also be needed on the degree of anisotropy in each region of the pelvic floor since this is also unknown. Finally, of particular interest are the viscoelastic properties of the pelvic floor and how pregnancy and labor affect these parameters. Some work has been done on the post mortem 3D morphology of the pelvic floor muscles for finite element models, ${ }^{54}$ however, the lack of muscle tone in post mortem specimens causes irreversible changes in the normal in vivo $3 \mathrm{D}$ geometry as well as possibly in the muscle fiber lengths. It is clear that data on the 3D shape of the pelvic floor post mortem should not be input 


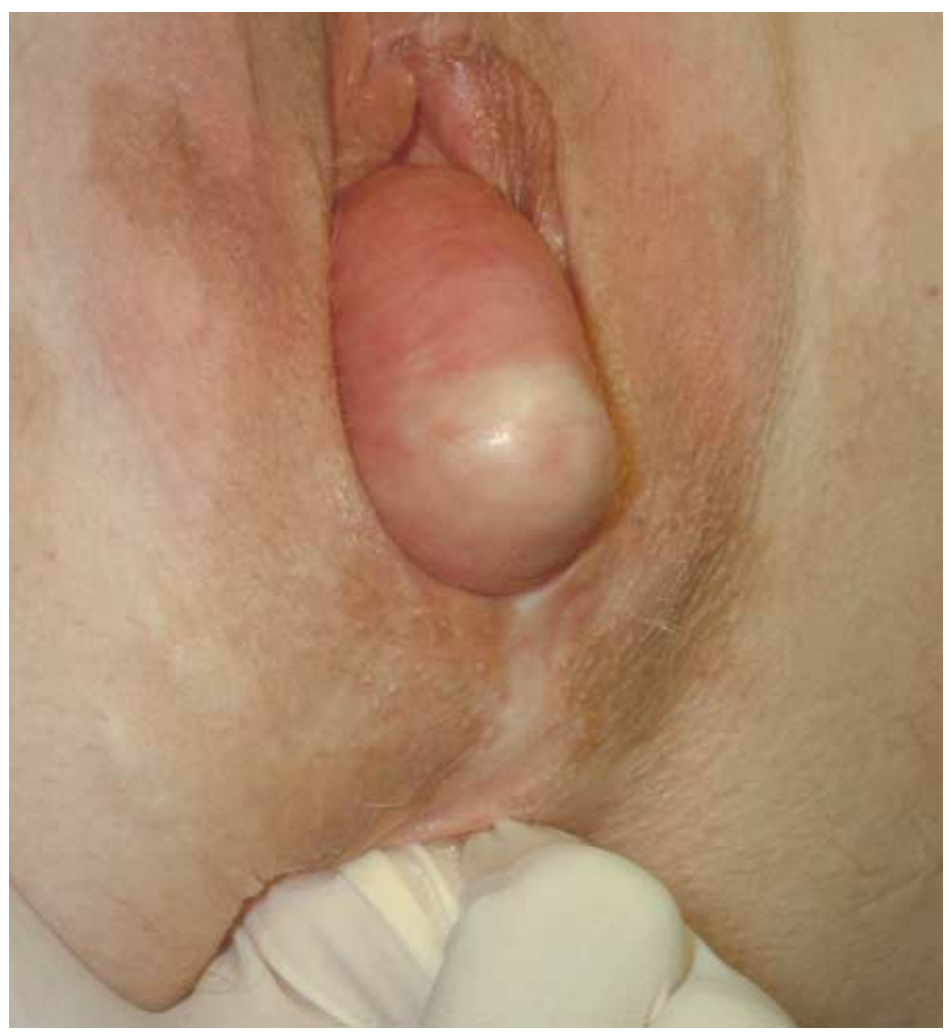

FIGURE 14. Mid-vaginal posterior prolapse that protrudes through the introitus despite a normally supported perineal body. (C) DeLancey 2004)

as geometric data to a finite element model of the pelvic floor in vivo because of the unrealistic bowl-like shape and exaggerated levator hiatus caused by muscle relaxation. In summary, the medial pubovisceral muscles were found to undergo the largest stretch of any levator ani muscles during vaginal birth. They therefore appear to be at the greatest risk for stretch-related injury. Recent imaging studies have demonstrated that levator ani muscle damage can occur at vaginal birth ${ }^{55-58}$ and the defects tend to occur near the origin of the pubovisceral muscles from the pubic bone. In the case of the de novo stress urinary incontinence, use of forceps, anal sphincter laceration, and episiotomy increased the odds ratio for levator muscle injury by $14.7,8.1$, and 3.1-fold, respectively. ${ }^{58}$

Indeed, excessive stretch of a striated muscle is a well-known cause of muscle injury: the more mechanical work done on a striated muscle in a lengthening contraction, the higher the risk for stretch-related injury. ${ }^{59}$ For maximally 


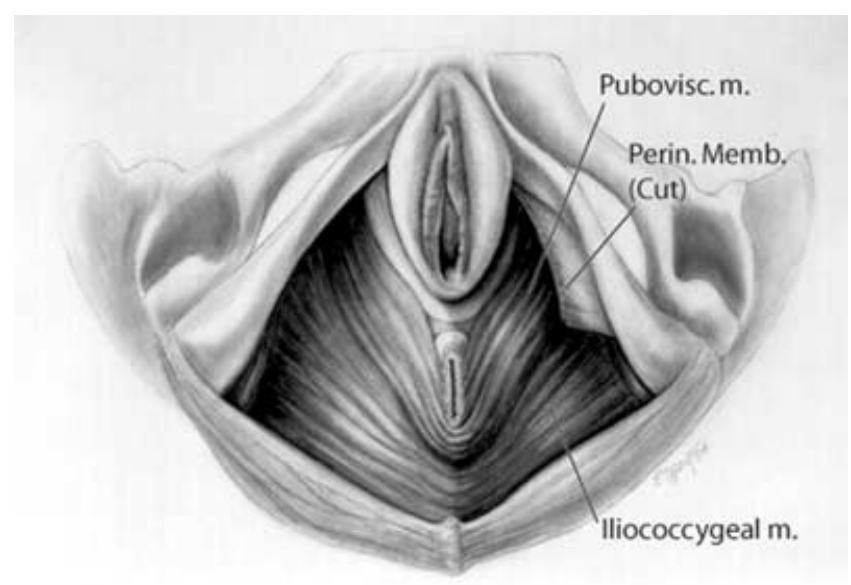

FIGURE 15. Levator ani muscles seen from below the edge of the perineal membrane ('urogenital diaphragm') can be seen on the left of the specimen. (c) DeLancey 1999)

activated muscles, the best predictors of injury are the magnitude of stretch (strain), or the product of force and strain (work), with strain and work being essentially equivalent in their predictive value. ${ }^{60}$ The same authors found that

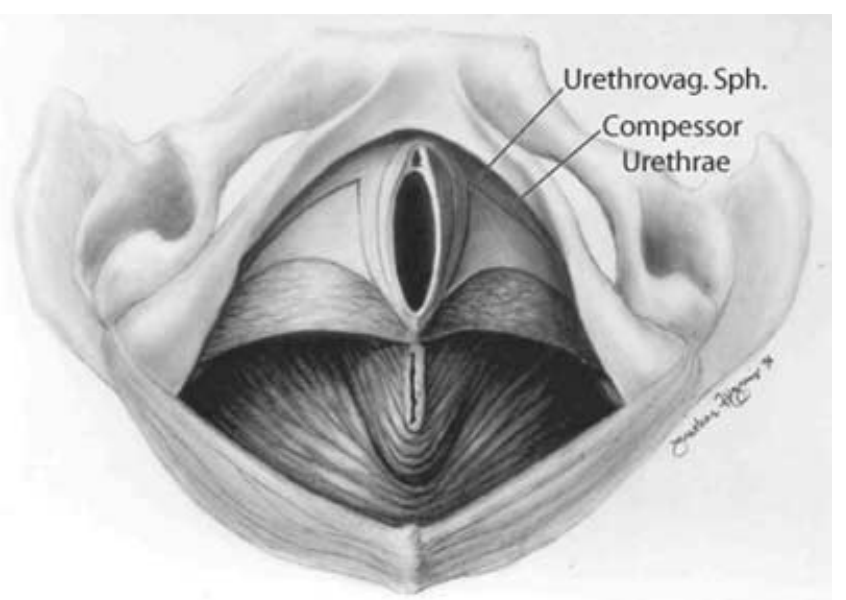

FIGURE 16. Position of the perineal membrane and its associated components of the striated urogenital sphincter, the compressor urethra, and the urethrovaginal sphincter. (c) DeLancey 1999) 


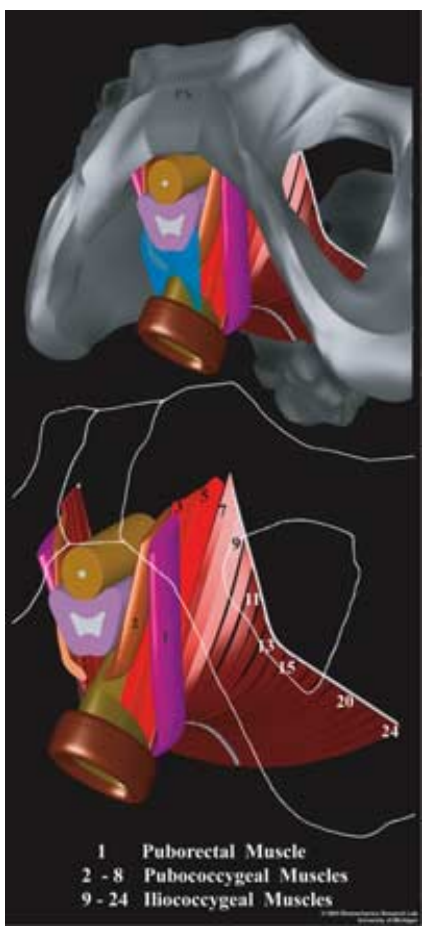

FIGURE 17. (Top) Inferior three-quarter view, seen from the left, of the pelvic floor structures appearing behind the ischiopubic rami (grey). That portion of the perineal membrane (blue) connecting the puboperineus muscles in the perineal body is shown. The lateral portions of the perineal membrane have been removed. (Bottom) The pelvic bones (outlined from image above in white) and perineal body have been removed to show a close-up of the arrangement of the iliococcygeal, pubococcygeal, and puborectalis muscles, as well as the urethra (umber), vagina (pink), and rectum (brown). Individual muscle bands are identified by a number inscribed near their origin on the arcus tendineus (white). The puboperineus muscle (2) is part of the pubococcygeal muscle. This figure appears in color online (From Lien et al., ${ }^{53}$ 2004)

the best predictor of injury in live passive muscle, as measured by the force deficit after a minute, was the work done on the muscle. Injury to individual fibers is initiated by focal mechanical damage to specific groups of sarcomeres, ${ }^{60}$ but injury can of course also occur at higher levels of this hierarchically organized structure.

Although stretch-related injury remains the most plausible injury mechanism, alternative mechanisms of pelvic muscle injury involve nerve compression or even a compartment syndrome caused by direct compression by the fetal head. The possibility that these types of injury cause pelvic floor damage might be worth investigating. 


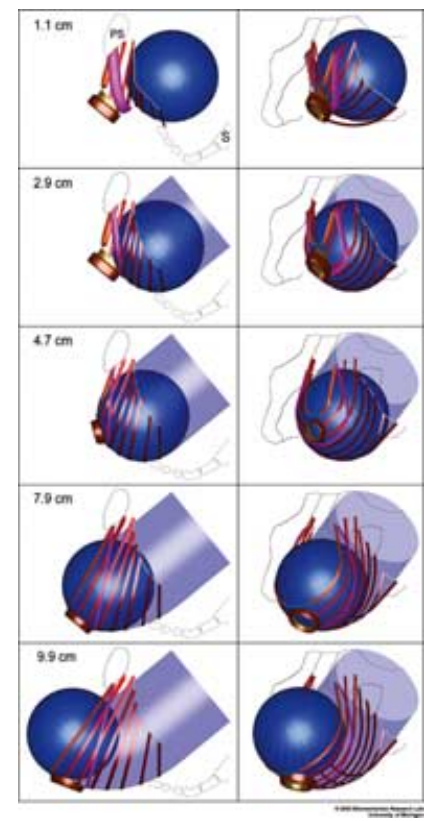

FIGURE 18. Simulated effect of fetal head descent on pelvic floor muscles in the second stage of labor. At top left, a left lateral view shows the fetal head (blue) located posteriorly and inferiorly to the pubic symphysis (PS) in front of the sacrum (S). The sequence of five images at left show the fetal head as it descends $0.6,2.5,6.4,10.0$, and $12.0 \mathrm{~cm}$ below the ischial spines as the head passes along the Curve of Carus (indicated by the transparent, light blue, curved tube). The sequence of five images at right are frontleft, three-quarter views corresponding to those shown at left. This figure appears in color online. (From Lien et al., ${ }^{53}$ 2004)

\section{Pelvic Nerve Stretch}

A computer simulation has also been used to estimate the strain in the nerves innervating the levator ani, urethra, and anal sphincter during the second stage of vaginal labor. ${ }^{61}$ In this study the increase in pudendal nerve branch lengths was calculated using a 3D computer model of vaginal delivery. The main inferior rectal and perineal branches of the pudendal nerve were dissected in 12 hemi-pelves from 6 adult female cadavers. Their 3D courses were digitized in the four specimens with the most characteristic nerve branching pattern, and the data were imported into a published 3D computer model of the pelvic floor. ${ }^{53}$ Each nerve branch was then represented by a stretchable cord with a fixation point at the ischial spine. The length change in each branch was then quantified as the fetal head descended through the pelvic floor. The maximum nerve strains ([(final length-original length)/original length] $* 100)$ were calculated for 5 degrees of perineal descent: reference descent from the literature, $1.25 \mathrm{~cm}$ 

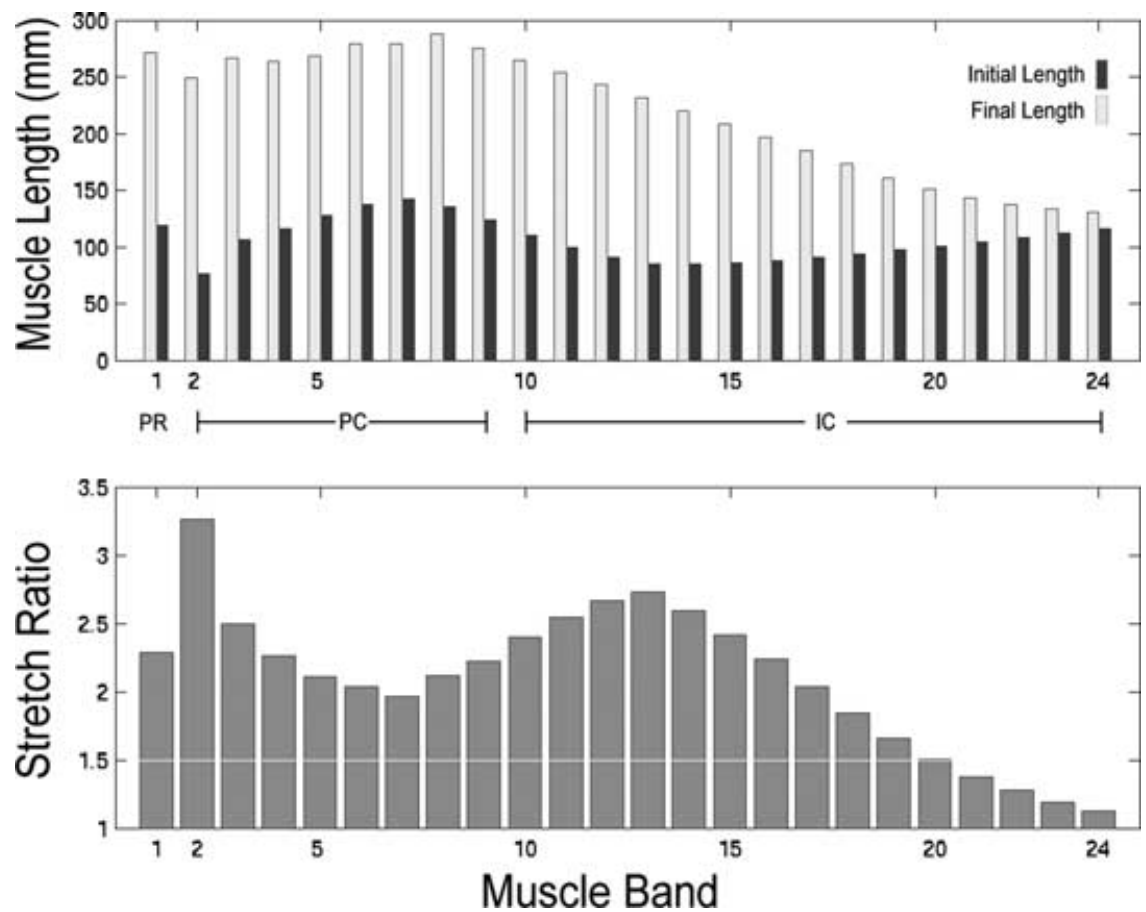

FIGURE 19. Final stretch ratios in each levator ani muscle slip (see Figure 17) at the end of the second stage of labor. (From Lien et al., ${ }^{53}$ 2004)

and $2.5 \mathrm{~cm}$ caudal and cephalad. The effect of alternative fixation points on resultant nerve strain was also studied. The results showed that the inferior rectal branch exhibited the maximum strain, $35 \%$, and this strain varied by $15 \%$ from the scenario with the least perineal descent to that with the most perineal descent. The strain in the perineal nerve branch innervating the anal sphincter reached $33 \%$, while the branches innervating the posterior labia and urethral sphincter reached values of $15 \%$ and $13 \%$, respectively. The more proximal the nerve fixation point, the greater the nerve strain. Thus, during the second stage the nerves innervating the anal sphincter are stretched beyond the $15 \%$ strain threshold known to cause permanent damage in appendicular peripheral nerve, and the degree of perineal descent is shown to influence pudendal nerve strain.

\section{CONCLUDING REMARKS}

There are many opportunities for meaningful biomechanical research into the normal structure-function relationships in the female pelvic floor both in the nonpregnant state, the pregnant state, and most especially, during the 
second stage of vaginal birth, which is associated with an unusually high maternal injury rate. The advent of modern $3 \mathrm{D}$ imaging techniques offers unparalleled opportunities for studying pelvic floor function in living women, and for developing anatomically accurate subject-specific computer models of the complex tissue interactions that can occur.

\section{ACKNOWLEDGMENTS}

This study was supported by Public Health Service Grants P50 HD044406, P30 AG 024824, and R01 HD 038665.

\section{REFERENCES}

1. Olsen, A.L., V.J. Smith, J.O. Bergstrom, et al. 1997. Epidemiology of surgically managed pelvic organ prolapse and urinary incontinence. Obstet. Gynecol. 89: 501-506.

2. Herzog, A.R., A.C. Diokno, M.B. Brown, et al. 1990. Two-year incidence, remission, and change patterns of urinary incontinence in noninstitutionalized older adults. J. Gerontol. 45: M67-M74.

3. Thomas, T.M., K.R. Plymat, J. Blannin, et al. 1980. Prevalence of urinary incontinence. Brit. Med. J. 281: 1243-1245.

4. Diokno, A.C., T.J. Wells \& C.A. BrinK. 1987. Urinary incontinence in elderly women: urodynamic evaluation. J. Am. Geriatr. Soc. 35: 940-946.

5. Bergman, A. \& G. EliA. 1995. Three surgical procedures for genuine stress incontinence: Five-year follow-up of a prospective randomized study. Am. J. Obstet. Gynecol. 173: 66-71.

6. Colombo, M., S. Scalambrino, A. Maggioni, et al. 1994. Burch colposuspension versus modified Marshal-Marchetti-Krantz urethropexy for primary genuine stress urinary incontinence: a prospective, randomized clinical trial. Am. J. Obstet. Gynecol. 171: 1573-1579.

7. MANT, J., R. PAINTER \& M. VeSSEY. 1997. Epidemiology of genital prolapse: observations from the Oxford Planning Association Study. Brit. J. Obstet. Gynaecol. 104: 579-585.

8. ENhöRning, G. 1961. Simultaneous recording of intravesical and intra-urethral pressure. Acta Chir. Scand. 276(Suppl): 1-68.

9. Kim, K-J., J.A. Ashton-Miller, K. Strohbehn, et al. 1997. The vesico-urethral pressuregram analysis of urethral function under stress. J. Biomech. 30: 19-25.

10. DeLancey, J.O.L. 1994. Structural support of the urethra as it relates to stress urinary incontinence: the hammock hypothesis. Am. J. Obstet. Gynecol. 170: 1713-1723

11. Strohbehn, K., L.E. Quint, M.R. Prince, et al. 1996. Magnetic resonance imaging anatomy of the female urethra: a direct histologic comparison. Obstet. Gynecol. 88: $750-756$.

12. Strohbehn, K. \& J.O.L. DeLancey. 1997. The anatomy of stress incontinence. Op. Tech. Gynecol. Surg. 2: 15-16. 
13. Rud, T., K.E. Andersson, M. Asmussen, et al. 1980. Factors maintaining the intraurethral pressure in women. Invest. Urol. 17: 343-347.

14. DeLancey, J.O.L. 1986. Correlative study of paraurethral anatomy. Obstet. Gynecol. 68: 91-97.

15. Gosling, J.A., J.S. DiXon, H.O.D. Critchley, et al. 1981. A comparative study of the human external sphincter and periurethral levator ani muscles. Brit. J. Urol. 53: $35-41$.

16. DeLancey, J.O.L. \& J.A. Ashton-Miller. 2004. Pathophysiology of adult urinary incontinence. Gastroenterology 126(Suppl 1): S23-S32.

17. Hilton, P. \& S.L. Stanton. 1983. Urethral pressure measurement by microtransducer: the results in symptom-free women and in those with genuine stress incontinence. Brit. J. Obstet. Gynaecol. 90: 919-933.

18. Smith, A.R.B., G.L. Hosker \& D.W. Warrell. 1989a. The role of partial denervation of the pelvic floor in the aetiology of genitourinary prolapse and stress incontinence of urine: a neurophysiological study. Brit. J. Obstet. Gynaecol. 96: 24-28.

19. Smith, A.R.B., G.L. Hosker, D.W. Warrell. 1989b. The role of pudendal nerve damage in the aetiology of genuine stress incontinence in women. Brit. J. Obstet. Gynaecol. 96: 29-32.

20. Snooks, S.J., M. Swash, M.M. Henry, et al. 1986. Risk factors in childbirth causing damage to the pelvic floor innervation. Int. J. Colorectal Dis. 1: 20-24.

21. Perucchini, D., J.O.L. DeLancey, J.A. Ashton-Miller, et al. 2002a. Age effects on urethral striated muscle: I. Changes in number and diameter of striated muscle fibers in the ventral urethra. Am. J. Obstet. Gynecol. 186: 351-355.

22. Perucchini, D., J.O.L. DeLancey, J.A. Ashton-Miller, et al. 2002b. Age effects on urethral striated muscle: II. Anatomic location of muscle loss. Am. J. Obstet. Gynecol. 186: 356-360.

23. Pandit, M., J.O.L DeLancey, J.A. Ashton-Miller, et al. 2000. Quantification of intramuscular nerves within the female striated urogenital sphincter muscle. Obstet. Gynecol. 95(6 Pt 1): 797-800.

24. Skelton, D.A., A. Young, C.A. Greig, et al. 1995. Effects of resistance training on strength, power, and selected functional abilities of women aged 75 and older. J. Am. Geriatr. Soc. 43: 1081-1087.

25. Porges, R.F., J.C. Porges \& G. Blinick. 1960. Mechanisms of uterine support and the pathogenesis of uterine prolapse. Obstet. Gynecol. 15: 711-726.

26. Halban, J. \& I. TANDler I. 1907. Anatomie und Aetiologie der Genitalprolapse beim Weibe, Vienna.

27. Berglas, B. \& I.C. Rubin. 1953. Study of the supportive structures of the uterus by levator myography. Surgery, Gynecol. Obstet. 97: 677-692.

28. Kirschner-Hermanns, R., B. Wein, S. Niehaus, et al. 1993. The contribution of magnetic resonance imaging of the pelvic floor to the understanding of urinary incontinence. Brit. J. Urol. 72(5 Pt 2): 715-718.

29. TunN, R., S. PARIS, W. FISCHER, et al. 1998. Static magnetic resonance imaging of the pelvic floor muscle morphology in women with stress urinary incontinence and pelvic prolapse. Neurourol. Urodyn. 17: 579-589.

30. Koelbl, H., V. SAZ, D. Doerfler, et al. 1998. Transurethral injection of silicone microimplants for intrinsic urethral sphincter deficiency. Obstet. Gynecol. 92: 332-336.

31. Hanzal, E., E. Berger \& H. Koelbl. 1993. Levator ani muscle morphology and recurrent genuine stress incontinence. Obstet. Gynecol. 81: 426-429. 
32. KeARney, R., R. SAWhney \& J.O.L DeLAnCEy. 2004. Levator ani muscle anatomy evaluated by origin-insertion pairs. Obstet. Gynecol. 104: 168-173.

33. TAVERNER, D. 1959. An electromyographic study of the normal function of the external anal sphincter and pelvic diaphragm. Dis. Colon. Rectum 2: 153-160.

34. Parks, A.G., N.H. Porter \& J. Melzak. 1962. Experimental study of the reflex mechanism controlling muscles of floor. Dis. Colon Rectum 5: 407-414.

35. Paramore, R.H. 1918. The uterus as a floating organ. In The Statics of the Female Pelvic Viscera, Ed.: 12. HK Lewis and Company. London.

36. DeLancey, J.O.L., R. KeARney, Q. Chou, et al. 2003. The appearance of levator ani muscle abnormalities in magnetic resonance images after vaginal delivery. Obstet. Gynecol. 101: 46-53.

37. Howard, D., J.M. Miller, J.O.L. DeLancey, et al. 2000a. Differential effects of cough, valsalva, and continence status on vesical neck movement. Obstet. Gynecol. 95: 535-540.

38. Blandpied, P. \& G.L. SmidT. 1993. The difference in stiffness of the active plantarflexors between young and elderly human females. J. Gerontol. 48: M58-M63.

39. Richardson, A.C., P.B. Edmonds \& N.L. Williams. 1981. Treatment of stress urinary incontinence due to paravaginal fascial defect. Obstet. Gynecol. 57: 357362.

40. DeLAnCEY, J.O.L. 1990. Anatomy and physiology of urinary continence. Clin.Obstet.Gynecol. 33: 298-307.

41. Allen, R.E., G.L. Hosker, A.R.B. Smith, et al. 1990. Pelvic floor damage and childbirth: a neurophysiological study. Brit.J. Obstet. Gynaecol. 97: 770779.

42. Miller, J.M., D. Perucchini, L.T. Carchidi, et al. 2001. Pelvic floor muscle contraction during a cough and decreased vesical neck mobility. Obstet. Gynecol. 97: 255-260.

43. Ashton-Miller, J.A., J.O.L. DeLancey \& D.N. Warwick. 2002. Method and Apparatus for Measuring Properties of the Pelvic Floor Muscles. US Patent 6,468,232 B1.

44. SAmpselle, C.M., J.M. Miller, B. Mims, et al. 1998. Effect of pelvic muscle exercise on transient incontinence during pregnancy and after birth. Obstet. Gynecol. 91: 406-412.

45. Howard, D., J.O.L. DeLancey, R. Tunn, et al. 2000b. Racial differences in the structure and function of the stress urinary continence mechanism in women. Obstet. Gynecol. 95: 713-717.

46. Thelen, D.G., J.A. Ashton-Miller, A.B. Schultz, et al. 1996a. Do neural factors underlie age differences in rapid ankle torque development? J. Am. Geriatr. Soc. 44: 804-808.

47. Thelen, D.G., A.B. Schultz, N.B. Alexander, et al. 1996b. Effects of age on rapid ankle torque development. J. Gerontol. A. Biol. Sci. Med. Sci. 51: M226M232.

48. Sinkjaer, T., E. Toft, S. Andreassen, et al. 1988. Muscle stiffness in human ankle dorsiflexors: intrinsic and reflex components. J. Neurophysiol. 60: 11101121.

49. Klutke, G.C., J. Golomb, Z. BArbaric, et al. 1990. The anatomy of stress incontinence: magnetic resonance imaging of the female bladder neck and urethra. J. Urol. 43: 563-566.

50. Bø, K. \& T. TALSETH. 1996. Long-term effect of pelvic floor muscle exercise 5 years after cessation of organized training. Obstet. Gynecol. 87: 261-265. 
51. Miller, J.M., J.A. Ashton-Miller \& J.O.L. DeLAnCEy. 1998a. Quantification of cough-related urine loss using the paper towel test. Obstet. Gynecol. 91(5 Pt 1): 705-709.

52. Miller, J.M., J.A. Ashton-Miller \& J.O.L. DeLancey. 1998b. A pelvic muscle precontraction can reduce cough-related urine loss in selected women with mild SUI. J. Am. Geriatr. Soc. 46: 870-874.

53. Lien, K-C., B. Mooney, J.O.L. DeLAnCEY, et al. 2004. Levator ani muscle stretch induced by simulated vaginal birth. Obstet. Gynecol. 103: 31-40.

54. JANDA, S., F.C.T. VAN DER HELM \& S.B. DEBloK. 2003. Measuring morphological parameters of the pelvic floor for finite element modeling purposes. J. Biomech 36: 749-757.

55. TunN, R., J.O.L DeLANCEY, D. Howard, et al. 1999. MR Imaging of levator ani muscle recovery following vaginal delivery. Int. Urogynecol. J. 10: 300-307.

56. Hoyte, L., L. Schierlitz, K. Zou, et al. 2001. Two- and 3-dimensional MRI comparison of levator ani structure, volume, and integrity in women with stress incontinence and prolapse. Am. J. Obstet. Gynecol. 185: 13-19.

57. Dietz, H.P. \& V. LANZARONE. 2005. Levator trauma after vaginal delivery. Obstet. Gynecol. 106: 707-712.

58. KeArney, R., J.M. Miller, J.A. Ashton-Miller, et al. 2006. Obstetric factors associated with levator ani muscle injury after vaginal birth. Obstet. Gynecol. 107:144-149.

59. Brooks, S.V. \& J.A. FAULKNER. 1992. Isometric, shortening, and lengthening contractions of muscle fiber segments from adult and old mice. Am. J. Physiol. 267(2 Pt 1): C507-C513.

60. Brooks, S.V., E. Zerba \& J.A. FaulKner. 1995. Injury to muscle fibres after single stretches of passive and maximally stimulated muscles in mice. J. Physiol. (Lond.) 488(Pt 2): 459-469.

61. Lien, K-C., D.M. Morgan, J.O.L. DeLancey, et al. 2005. Pudendal nerve stretch during vaginal birth: a 3-D computer simulation. Am. J. Obstet. Gynecol. 192: 1669-1676. 